
\title{
S Research Square \\ COVID-19 Infection Manifesting as a Severe Gastroparesis Flare: A Case Report
}

\section{Jun Song, MD ( $\nabla$ junhansong@gmail.com )}

Temple University Hospital https://orcid.org/0000-0002-1195-2088

\section{Rajiv Bhuta, MD}

Temple University Hospital

\section{Kamal Baig, MD}

Temple University Hospital

Henry P. Parkman, MD

Temple University Hospital

\section{Zubair Malik, MD}

Temple University Hospital

\section{Case Report}

Keywords: COVID-19, Coronavirus, Gastroparesis, Gastrointestinal Symptoms

Posted Date: June 15th, 2020

DOI: https://doi.org/10.21203/rs.3.rs-28584/v1

License: (c) (1) This work is licensed under a Creative Commons Attribution 4.0 International License. Read Full License

Version of Record: A version of this preprint was published at Medicine on April 9th, 2021. See the published version at https://doi.org/10.1097/MD.0000000000025467. 


\section{Abstract}

Background: Coronavirus Disease 2019 (COVID-19) is a disease caused by infection with Severe Acute Respiratory Syndrome Coronavirus 2 (SARS-CoV-2), which commonly presents with symptoms including fever, cough, and dyspnea. More recently, however, some patients have tested positive for COVID-19 after developing gastrointestinal (GI) symptoms either solely or in conjunction with respiratory symptoms. This may be due to SARS-CoV-2 infection of the GI tract. In patients with chronic GI illnesses, COVID-19 may initially present as a flare of their underlying $\mathrm{GI}$ conditions as viruses have historically been implicated in exacerbations of GI disorders, including gastroparesis.

Case presentation: We report a case of a 37 year-old female with a history of diabetic gastroparesis who presented to the Emergency Department (ED) in a gastroparesis flare. Her symptoms in the ED failed to improve with fluids and anti-emetic medications. After developing a fever, she was tested and found to be positive for COVID-19.

Conclusion: To our knowledge, at the present time, this is the first report of a patient with COVID-19 presenting with signs and symptoms of a gastroparesis flare. This case illustrates that patients with underlying GI disorders, such as gastroparesis, may have SARS-CoV-2 infections that present as an exacerbation of their underlying disorder. Initial presentation of these patients manifesting as a flare of their chronic GI disease, more severe than usual, should prompt an index of suspicion for COVID-19.

\section{Background}

Coronavirus Disease 2019 (COVID-19) is a disease caused by infection with Severe Acute Respiratory Syndrome Coronavirus 2 (SARS-CoV-2). Since the initiation of the COVID-19 pandemic, patients with SARS-CoV-2 infections have primarily presented with respiratory symptoms as the virus mainly targets the respiratory tract ${ }^{1}$. This predilection for the respiratory system may, in part, be due to pre-existing pulmonary comorbidities ${ }^{2}$. However, a minority of patients have now been documented to initially exhibit gastrointestinal (GI) symptoms including nausea, vomiting, and diarrhea ${ }^{3,4}$. The etiology for these $\mathrm{GI}$ symptoms secondary to SARS-CoV-2 infection is currently not well understood ${ }^{5}$. It is possible that chronic GI disorders may similarly predispose patients to primary GI infections from SARS-CoV-2 and manifest COVID-19 as a flare of their underlying disease. Herein, we report a case of a 37 year-old female with diabetic gastroparesis who tested positive for COVID-19 after she presented to the Emergency Department (ED) for intractable emesis, thought to be a flare of her gastroparesis.

\section{Case Report/case Presentation}

A 37 year-old female with a history of diabetic gastroparesis presented with 2 days of intractable nausea and vomiting. She was diagnosed with type II diabetes mellitus prior to 2017 at an outside institution, 
now treated with insulin. Prior upper endoscopy was negative and prior gastric emptying study was significant for $87 \%$ retention of radiolabeled meal at two hours (normal $<60 \%$ ) and $77 \%$ at four hours (normal<10\%). At presentation in the ED, the emesis was non-bloody, non-bilious, and associated with mild epigastric pain. Review of systems was negative for fevers or respiratory symptoms. Vital signs were within normal range. The cause of her symptoms was initially attributed to a gastroparesis flare in the setting of medication non-compliance as she had multiple ED visits in the past with similar presentations controlled with pharmacological treatment. She was discharged after a trial of metoclopramide administration. She returned the next day with worsening nausea and vomiting, which were described as significantly increased from her baseline gastroparesis flares, refractory to pharmacological therapy. Vitals were significant for a temperature of $100.4^{\circ} \mathrm{F}$. Laboratory tests were notable for a Hemoglobin A1c of 7.2\% (normal: $4.7-6.4 \%$ ) and a lymphopenia (white blood cell count: $3.4 \mathrm{~K} / \mathrm{mm}^{3}$, normal: $4.0-11.0 \mathrm{~K} / \mathrm{mm}^{3}$ ), reduced by about $5 \mathrm{~K} / \mathrm{mm}^{3}$ from her baseline. Six hours after initial triage, she developed a fever of $101.4^{\circ} \mathrm{F}$. A chest $\mathrm{x}$-ray and the CT Abdomen and Pelvis were unremarkable. The CT Chest (fig. 1), however, showed multi-focal ground glass opacities predominantly in the lung bases compatible with a viral/atypical pneumonia. A nasopharyngeal COVID-19 test was obtained, antibiotics were started empirically, and she was admitted to the hospital. On day 2 of admission, the gastroenterology service was consulted for the management of her gastroparesis flare and recommended continuing pantoprazole, changing the administration of ondansetron and metoclopramide to standing medications, and starting mirtazapine. During this time, her COVID-19 test resulted positive. She was started on antibiotics (azithromycin and ceftriaxone), steroids, and entered into a Remdesivir clinical trial. Her aspartate aminotransferase values had an upward trend from Day 2 to Day 3: $21 \mathrm{U} / \mathrm{L}, 21 \mathrm{U} / \mathrm{L}, 40 \mathrm{U} / \mathrm{L}, 50 \mathrm{U} / \mathrm{L}$, normal range: $15-37 \mathrm{U} / \mathrm{L})$. Her Gl symptoms improved and she became afebrile by day 4 , and she was discharged on day 5 . She was instructed to continue taking mirtazapine and ondansetron to manage her gastroparesis as well as antibiotics, steroids, and Remdesivir for COVID-19.

\section{Discussion And Conclusion}

This case report illustrates that COVID-19 infection can present as a flare of gastroparesis. The important take home message is that in patients with an exacerbation of a chronic illness, such as gastroparesis, one should consider COVID-19 as a potential etiology for the worsening of a previously stable chronic disorder.

The majority of patients with COVID-19 have currently presented with respiratory symptoms ${ }^{1,6}$. However, more patients are starting to present with GI symptoms either solely or in conjunction with pulmonary manifestations $\mathrm{s}^{3,7}$. This involvement with the $\mathrm{Gl}$ tract has also been reflected in reports of patients testing positive for infection in fecal samples, some of these negative in nasopharyngeal and sputum samples ${ }^{8}$. Immunofluorescence studies by Xiao et. al have shown that the SARS-CoV-2 ACE2 protein cell receptor is expressed in the glandular cells of gastric, duodenal, and rectal epithelia potentially allowing viral entry into these cells ${ }^{9}$. These are the same cell receptors found in the bronchial epithelial cells in the lower 
respiratory tract responsible for SARS-CoV-2 infection in the respiratory system ${ }^{10}$. Other coronaviruses that have also caused respiratory syndromes such as Middle East Respiratory Syndrome Coronavirus and SARS-CoV-1 have similarly been found to infect intestinal cells and spread through a fecal-oral route ${ }^{11-}$ 13. Taken together, it may be possible that the GI tract is also serving as a nidus for SARS-CoV-2 infection. Though, the predilection of SARS-CoV-2 for either the pulmonary system or the GI tract is not well understood despite similar infection mechanisms.

In epidemiologic studies, comorbidities of patients may be a risk factor for infection with SARS-CoV-2. In a meta-analysis including 1,576 patients, respiratory system diseases were among the most prevalent comorbidities affecting those with COVID-19 presenting primarily with respiratory symptoms ${ }^{14}$. Furthermore, Leung et. al found that patients with Chronic Obstructive Pulmonary Disease (COPD) have upregulated airway expression of the ACE2 protein cell receptor, which may increase the risk of patients with COPD to SARS-CoV-2 infection ${ }^{10}$. This suggests that comorbidities may play a role in the pathogenesis of SARS-CoV-2. In a recent study of 116 patients with COVID-19 who initially presented with cough, fever, and dyspnea as the main presenting symptoms, nearly a third of the patients were reported to develop GI symptoms later in the course of their infection ${ }^{5}$. In this series, $20.7 \%$ of patients had chronic pulmonary disorders and $26.1 \%$ had a smoking history, while there were no patients with underlying GI disorders and only $2.8 \%$ had chronic liver disease. The pulmonary comorbidities may have served as a risk factor for initial pulmonary infection in this cohort of patients. The infection may have subsequently propagated to the GI tract, demonstrated by the delay in GI symptoms, as receptors for SARS-CoV-2 have been found to be present in multiple organ systems ${ }^{15}$. This would suggest that comorbidities may play a key role in the initial pathogenesis of SARS-CoV-2. In the context of our patient, this may explain why she developed evidence of pulmonary disease on imaging despite presenting solely with GI symptoms. Her underlying gastroparesis may have predisposed her to infection with SARS-CoV-2 in the $\mathrm{GI}$ tract as evidenced by her symptom severity and uptrending liver enzyme values ${ }^{16}$. Her infection may have subsequently spread to her lungs as manifested by the multi-focal ground glass opacities found on imaging. Further research is needed to determine if patients are at higher risk for SARS-CoV-2 infection in the GI tract with certain chronic GI conditions.

Though it is possible that her intractable nausea and vomiting were entirely independent of her gastroparesis perhaps due to the COVID-19 virus infection itself, an exacerbation of gastroparesis from the COVID-19 virus is the likely scenario, as viruses have been implicated in the pathogenesis of gastroparesis ${ }^{17,18}$. In one study investigating the etiology of the disorder, $23 \%$ of patients with gastroparesis have been described as having postinfectious gastroparesis from a prior viral infection ${ }^{19}$. The proposed mechanism by which viruses can induce gastroparesis is through an acute injury to either the neural innervation of the stomach or the interstitial cells of Cajal in the stomach causing delayed gastric emptying ${ }^{20}$. Similarly, infections have also been implicated in worsening of other chronic $\mathrm{GI}$ disorders, such as inflammatory bowel disease (IBD $)^{21}$. Kim et. al found that patients with ulcerative colitis (UC) with concomitant cytomegalovirus (CMV) infections had a higher frequency of IBD-related 
hospitalizations compared to patients with UC without CMV infections ${ }^{22}$. This increased morbidity in the cohort with CMV infections may be due to the ability of CMV proteins to enhance pro-inflammatory cytokines to worsen the inflammation causing a flare of their UC more severe than baseline ${ }^{23}$. Therefore, it is reasonable to suspect that a virus like SARS-CoV-2 could potentially exacerbate an underlying GI disorder causing a flare of the disease during the initial presentation of COVID-19.

To our knowledge, at the present time, this is the first case of COVID-19 initially manifesting with signs and symptoms of a gastroparesis flare. This unique case illustrates that patients with underlying $\mathrm{GI}$ disorders, such as gastroparesis, may be at risk for SARS-CoV-2 infection of the GI tract. Initial presentation of these patients may manifest as a flare of their chronic GI disease, more severe than usual - either from worsening of their underlying disorder, or symptoms from the COVID-19 virus itself.

\section{Abbreviations}

Coronavirus 2019 - COVID-19; Chronic Obstructive Pulmonary Disease - COPD; Cytomegalovirus - CMV; Emergency Department - ED; Gastrointestinal - Gl; Inflammatory Bowel Disease - IBD; Ulcerative Colitis - UC; Severe Acute Respiratory Syndrome Coronavirus 2 - SARS-CoV-2

\section{Declarations}

Ethics approval and consent to participate: Not applicable Informed consent was obtained for the case report

Availability of data and materials: Not applicable

Competing Interests: The authors declare that they have no competing interests

Funding: Not applicable

Authors Contributions: JS wrote and revised the manuscript. RB, KB, and HP revised the manuscript. ZM revised the manuscript and is the article guarantor.

Acknowledgements: Not applicable

\section{References}

1. Rothan HA, Byrareddy SN. The epidemiology and pathogenesis of coronavirus disease (COVID-19) outbreak. J Autoimmun. 2020. doi:10.1016/j.jaut.2020.102433

2. Emami A, Javanmardi F, Pirbonyeh N, Akbari A. Prevalence of Underlying Diseases in Hospitalized Patients with COVID-19: a Systematic Review and Meta-Analysis. Arch Acad Emerg Med. 2020.

3. Wong SH, Lui RN, Sung JJ. Covid-19 and the Digestive System. J Gastroenterol Hepatol. 2020. doi:10.1111/jgh.15047 
4. Huang $C$, Wang $Y$, Li X, et al. Clinical features of patients infected with 2019 novel coronavirus in Wuhan, China. Lancet. 2020. doi:10.1016/S0140-6736(20)30183-5

5. Cholankeril G, Podboy A, Aivaliotis VI, et al. High Prevalence of Concurrent Gastrointestinal Manifestations in Patients with SARS-CoV-2: Early Experience from California. Gastroenterology. 2020. doi:10.1053/j.gastro.2020.04.008

6. Gu J, Han B, Wang J. COVID-19: Gastrointestinal Manifestations and Potential Fecal-Oral Transmission. Gastroenterology. 2020. doi:10.1053/j.gastro.2020.02.054

7. Han C, Duan C, Zhang S, Spiegel B, Shi H. Digestive Symptoms in COVID-19 Patients with Mild Disease Severity: Clinical Presentation, Stool Viral RNA Testing, and Outcomes. Am J Gastroenterol. 2020.

8. Chen L, Lou J, Bai Y, Wang M. COVID-19 Disease With Positive Fecal and Negative Pharyngeal and Sputum Viral Tests. Am J Gastroenterol. 2020. doi:10.14309/ajg.0000000000000610

9. Xiao F, Tang M, Zheng X, Liu Y, Li X, Shan H. Evidence for Gastrointestinal Infection of SARS-CoV-2. Gastroenterology. 2020. doi:10.1053/j.gastro.2020.02.055

10. Leung JM, Yang CX, Tam A, et al. ACE-2 Expression in the Small Airway Epithelia of Smokers and COPD Patients: Implications for COVID-19. Eur Respir J. 2020. doi:10.1183/13993003.00688-2020

11. Zhou J, Li C, Zhao G, et al. Human intestinal tract serves as an alternative infection route for Middle East respiratory syndrome coronavirus. Sci Adv. 2017. doi:10.1126/sciadv.aao4966

12. Shi $X$, Gong E, Gao D, et al. Severe acute respiratory syndrome associated coronavirus is detected in intestinal tissues of fatal cases. Am J Gastroenterol. 2005. doi:10.1111/j.1572-0241.2005.40377.x

13. Abdullah ASM, Tomlinson B, Cockram CS, Thomas GN. Lessons from the severe acute respiratory syndrome outbreak in Hong Kong. Emerg Infect Dis. 2003. doi:10.3201/eid0909.030366

14. Yang J, Zheng Y, Gou X, et al. Prevalence of comorbidities and its effects in coronavirus disease 2019 patients: A systematic review and meta-analysis. Int J Infect Dis. 2020. doi:10.1016/j.ijid.2020.03.017

15. Muus $C$, Luecken MD, Eraslan G, et al. Integrated analyses of single-cell atlases reveal age, gender, and smoking status associations with cell type-specific expression of mediators of SARS-CoV-2 viral entry and highlights inflammatory programs in putative target cells. bioRxiv. January 2020:2020.04.19.049254. doi:10.1101/2020.04.19.049254

16. Fan Z, Chen L, Li J, et al. Clinical Features of COVID-19-Related Liver Damage. SSRN Electron J. 2020. doi:10.2139/ssrn.3546077

17. Uppalapati SS, Ramzan Z, Fisher RS, Parkman HP. Factors contributing to hospitalization for gastroparesis exacerbations. Dig Dis Sci. 2009. doi:10.1007/s10620-009-0975-1

18. Oh JJ, Kim CH. Gastroparesis After a Presumed Viral Illness: Clinical and Laboratory Features and Natural History. Mayo Clin Proc. 1990. doi:10.1016/S0025-6196(12)65125-8

19. Bityutskiy LP, Soykan I, McCallum RW. Viral Gastroparesis: A Subgroup of Idiopathic Gastroparesis Clinical Characteristics and Long-Term Outcomes. Am J Gastroenterol. 1997. 
20. Parkman HP. Idiopathic gastroparesis. Gastroenterol Clin North Am. 2015. doi:10.1016/j.gtc.2014.11.015

21. Kandiel A, Lashner B. Cytomegalovirus colitis complicating inflammatory bowel disease. Am J Gastroenterol. 2006. doi:10.1111/j.1572-0241.2006.00869.x

22. Kim JJ, Simpson N, Klipfel N, Debose R, Barr N, Laine L. Cytomegalovirus infection in patients with active inflammatory bowel disease. Dig Dis Sci. 2010. doi:10.1007/s10620-010-1126-4

23. Criscuoli V, Rizzuto MR, Cottone M. Cytomegalovirus and inflammatory bowel disease: Is there a link? World J Gastroenterol. 2006. doi:10.3748/wjg.v12.i30.4813

\section{Figures}

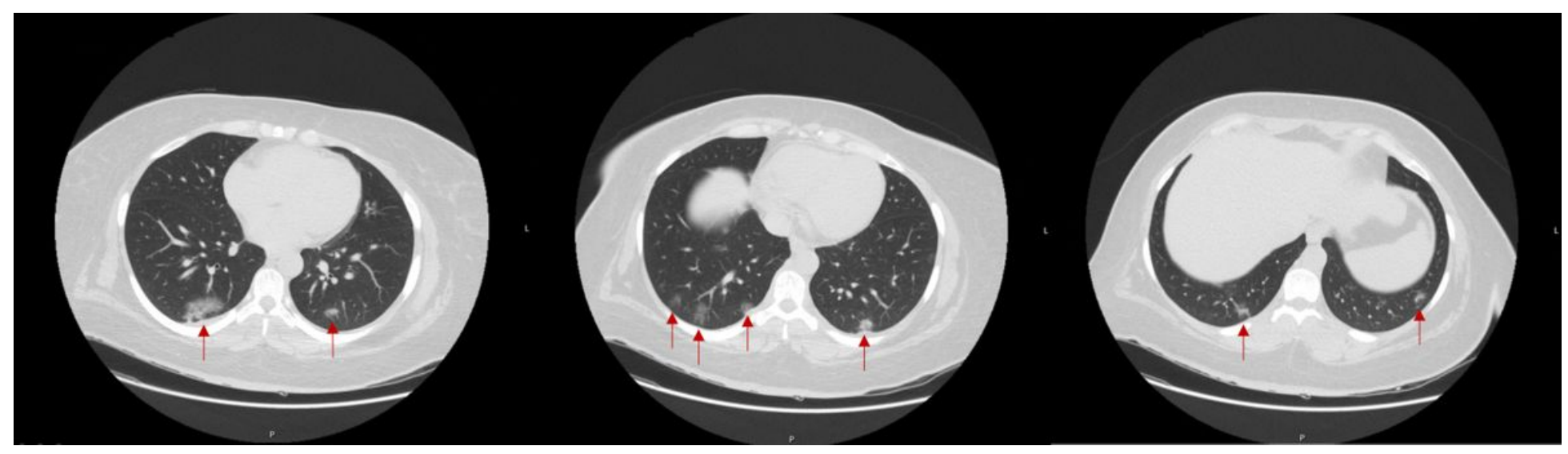

Figure 1

CT Chest shows multifocal lower lung predominant peripheral bronchocentric ground glass opacities (red arrows) compatible with viral/atypical pneumonia. 